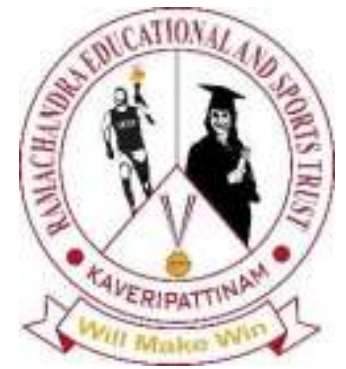

Recent trends in Management and Commerce

Vol: 2(1), 2021

REST Publisher

ISBN: 978-81-936097-6-7

Website: http://restpublisher.com/book-series/rmc/

\title{
A Review on Investment behavior and Decisions
}

Jaya K R, Pralhad Rathod

Department of Management Center for Management Studies (Jain Deemed to be University), Bengaluru, India. Department of Management Studies VTU, Belagavi, India.

Email: jayashetty.002@gmail.com

\begin{abstract}
Financial literacy is personal financial management Various finances including budget and investment Is the ability to understand and use skills effectively. Has been Investment behaviour, Investment pattern, Risk Preferences, Investment Decisions, Investment Choices, Financial literacy is the foundation of your relationship with money, and investing money in anticipation of a positive return / income in the future It is a lifetime journey to learn to do. In other words, investing is an asset with the goal of earning return on investment Or holding the object or increasing the value of Your investment is to increase the value of the property over a period of time. When a person invests, he should always sacrifice some of his assets, viz. Time, money or effort. An investor may lose some or all of the capital invested. Investment differs from neutral in that the investment is made without investment or with profit without risk. Savings bear the risk (usually remote) that the financier may default to. Forex Savings also have a foreign exchange risk: If the currency of the savings account differs from the account holder's household currency, the exchange rate between the two currencies will move unfavorably. Thus there is a risk that the value of the savings account will decrease. Measured in the holder's home currency. Even investing in such solid assets has its risks. As with most risks, property buyers can try to mitigate potential risk by taking out a mortgage and borrowing at a lower interest rate.
\end{abstract}

\section{Introduction}

How investors judge, predict, analyze and review practices Investment behaviours are defined as doing. Decision making This includes investment psychology, data collection, definition and understanding, and research. And analysis. Traditional finance has long held to the notion that investors are rational, unbiased, and risk averse. It also professes that investors' comfort level for risk is essentially stable and individuals will only accept higher levels of risk if offered adequate returns. Investment method of investors in Different Materials 2.2 Investment Process-Levels Investment Process The investment process is generally described in four stages. These levels include investment policy, investment analysis, bond valuation and portfolio construction. An investment is an asset or object acquired for the purpose of earning an income value. ... An investor, for example, may buy a property now for cash, with the expectation that the property will yield returns in the future or be sold at a higher price for profit. Among risks, basic behaviours can be divided into three types of risk options - risk neutrality, risk search and risk aversion. Those types specify the level of risk that is generally acceptable. Due to the expected return, the risk is variable; This is the chance of success or failure. Risk preferences are measured using studies with real effects or motivated games. Reviewing different approaches to measuring personal risk aversion shows that the best approach depends on the question being asked and the target population of the study. $\mathrm{q}$ is the market value of companies divided by the alternative cost of capital. When $\mathrm{q}$ is high, the market price of companies is high compared to the alternative cost of capital, Also new plant and equipment capital is cheaper compared to the market value of the companies. Companies can then issue shares and with the price of the facilities and equipment they purchase Can get a higher price compared to. As a result, investment costs will rise because companies can buy a lot of new investment products with a small share issue. In principle, for home investment decisions Similar reasons can be used. Definition: Investment decision is related to the decision made by the top management depending on the amount of funds to be used by the investors or investment opportunities. Selecting the type of assets to be invested by the company is called investment decision.

\section{Investment behavior}

Investment behaviour is based on uncertainty about the future and is thus risky. The speed and availability of news and rumours and information play an important role in investment markets. Risk pursuit, risk aversion and attitude are key concepts and explanations of investment behaviour. Investment behaviour is based on uncertainty about the future, Thus dangerous. The speed and availability of news and rumours and information play an important role in investment markets. ... Investors use pro and holistic in decisions such as whether or not to invest and how much to invest. In reviewing investment behaviour models, our second objective is to describe and evaluate alternative representations of the time framework of the underlying investment process. Finally, investment behaviour models differ in the treatment of alternative investment. If the substitution is proportional to the share of capital, the basic death distribution for the investment goods is geometric. The change in capital stock is equal to the total investment, which is less than the fixed ratio of capital shares, Capital equity is therefore a weighted sum of past total investments with geometrically declining weights, the first part of which is devoted to 

appropriate behaviour not to hit the brakes, and his fearlessness allowed him to function at his best. The broader motivation of current research is to explore this latter possibility, In some situations, more positive decisions can be made than in those who do not miss such reactions, on the contrary, research should determine which situation the emotions are in. Effective or disruptive, then a reasonable connection of circumstances and emotions may guide human behaviour [103]. Investing in the past by examining whether the buying rate of past winning shares is higher than the buying rate of past lost shares We study how it relates to income. More specifically, the investor-type investment method is measured as an estimate between the average of the buying ratios of four stocks with returns in the first quarter (16 shares) rather than the average of the buying ratios. Last return on four stocks in the lower quarter. If this respect is positive, the purchase rate for the last winning stock is the type of investor given the test figures for investor behaviour, the value of each day t purchase rate is used to calculate the level of behaviour of the investor (then, the performance measurement) independent of the relative correlations calculated at zero average and other dates [104]. Investor behaviour related to the key principle of diversification in personal portfolio selection was further explored by examining the relationship between different investment behaviours and portfolio diversification index. Behavioural process. In particular, it opens the question of whether there has been a positive change in the present in improving investment decision processes and investment outcomes for women. This study sheds light on some aspects of the investment decision-making process and leaves other dimensions open to future investigation. However, it is important for future researchers to continue some of these investigations in the long run [105]. However, the problem of assessment of the regression structure is intertwined with the subject matter of the basic model specification. It may be appropriate to use the "bottle-clay" hypothesis with the "neo-classical model", which includes comparative prices. It is based on the neo-classical theory of optimal accumulation of capital, a theory that differentiates between investment responses to changes in relative prices and changes in output. Investment behaviour provides a very satisfactory description of the actual investment costs for our model period. "8 This must be understood in context [107].

\section{Investment pattern}

Reports on international direct investment trends focus on recent developments. Similar information for policy makers and others interested in the pace and scale of globalization Although very relevant, it fails to provide any perspective on the nature of globalization. By their very nature, recent developments are putting more weight on the rotating element in global investment flows. Long-term orientation, self-efficacy, and other behavioural aspects were found to have a relationship with investment patterns as a result of women's empowerment. There is research gap in understanding what factors determine investment decision with different statistics of working women. Therefore, this study sought to understand the importance of awareness of investment options and the relationships related to factors affecting the investment preferences of salaried employees in the Northern Governorate, in order to attract more savings. It is recommended to improve their storage methods by attending training classes. Return on investment. Finance officials should organize savings habits and investment awareness classes to improve the economic status of individuals. The current study covers only the northern Ash Sharqia governorate of Oman. It is not good to generalize the results of this research to other regions or countries. Cross-national research is also recommended to understand investment plans and the behaviour of working women [36]. For financial literacy and family communication systems As the first research paper exploring the relationship between, this project can be considered a pioneering study. Data was collected through an online survey using Qualtrics. Research before participant recruitment Recognized by the IRB, this comparative consistency allows key variables to be considered without significant concern for demographic variables that could divert results. This research will help establish a relationship between financial literacy and family communication systems, and future jobs will explore and confirm this relationship in a wider population. , And many more linear regression. Differences between different groups used D-Test [66]. In addition, we examined the relative magnitude of the loss. The share of wealth lost to individuals with low financial literacy is about $2.2 \%$ and slightly higher to families with higher literacy (4. 9\%).Analysis reveals that. The conditional method for reporting a loss is reversed. Those in the lower financial literacy group report an average loss of $21.2 \%$ of their financial assets, while those with a higher financial literacy average lose an average of $17.9 \%$ of their assets. However, the difference between the two groups is small and insignificant, and the effect is small in many systems [7]. The investment system of the German economy was published after 1934; Investment structure information was provided to only a few specialized departments over a period of time. Despite many studies on this topic, German investment during the Third Reich The size and structure have not yet been definitively determined by the scholar. The fourth section presents and discusses the findings of the German investment system during the Nazi period. The fifth part provides some conclusions. To allow for easy reading, detailed assessment procedures and statistics are mainly found in the appendices. The investment system up to 1938 has some important gaps and open questions in public investment figures, such as the size of both military spending and arms purchases. In the years to come, From 1939 until the end of the war, our knowledge of the German investment system was still unsatisfactory [124]. The second case is a strong decision-making time-cantered and concentrated investment Indicates the method. In this case, all available resources are invested in the first two years, and the maximum technical share is next, The maximum technical stock simulated by various investment methods and technology stock accumulation is 58 points, and this investment method never achieves satisfactory performance. [125].

\section{Risk Preferences}

They sought to describe diagnostic behaviors and experiences, and they guessed their risk choice by focusing on voluntary, after-actions and experiences. We found that the respondents 'third party readers' brief memoirs and descriptions were identical assumptions Indicates the preferences of the respondents that this information is intermediate valid. Our results help to open up the self-awareness behind stated risk options, allowing people to gain through Their own understanding of what the diagnosis is behaviors and experiences are exposed to in high-role Situations in the real world. Reveal risk options and timing options, 
Jaya K R. et.al / Recent trends in Management and Commerce Vol: 2(1), 2021: 26-31

respondents participated in 8 multiple invoice (MBL) assignments, with subjects doing A total of four risk options and four time exams, which are standardized and accepted Manuscript 7 Modified Behavioral Economics and Neuroscience at the University of Cape Town, Cape Town (South Africa)) Suitable for the South African context. Graphical representations of the overall density of risk options index values show subjects with low financial literacy tend to prefer high risk Compared to subjects with higher financial literacy. Risk preferences, confidence levels, and financial literacy perceptions significantly affect the financial behavior of male students [38]. These findings point to a negative relationship between financial literacy and risk perception, This is because those who are more financially literate know more about investment products. For example, Hunter conducted his research with pilots to study pilot risk perception and reported a significant negative correlation between pilot risk perception score and their risk action involvement index.Similarly, in a financial context, Byrne explored the relationship between consumer financial perception and the investment allocation of various financial products. [61].In particular, we argue that more individuals in the NA should be more cautious and have a more optimistic outlook. That is, their cautious mindset, ultimately, and how personality influences the way they process risk and external network information [93]. Discussed in terms of consumer decision-making, the nature and extent of consumer perceived uncertainty in considering a particular purchase decision, uncertainty for financial products is implemented on the basis of loss of investment and perceived opportunity. There is a significant correlation effect between expert approval on the corporate image and the PE of individuals as well as the risk that a corporation poses when advertising its financial services [95]. Adverse The problem of choice arises when lenders fail to understand the true extent of the risks of financial securities and the moral risk problem arises when lenders fail to properly understand the intentions of borrowers.In both scenarios, lenders run the risk of losing money, thus reducing investment in the financial markets.One way to alleviate the problem of asymmetric information is to access information related to financial securities [10].Financial educated managers and directors are encouraged to participate in a variety of risk reduction strategies, including hedging and corporate monetary policy.In other words, the high performance of companies is made possible by more financially educated managers who reduce risk by modifying risk management strategies.It may be fair to say that business education (hereby referred to as financial education) helps entrepreneurs to be aware of risk controls and policies. Therefore, the alternative influence of education, thereby enhancing the risks of an entrepreneur, leads to more efficient organizational risk management practices:It is true that ERM procedures are measured with different dimensions [29].Because of the ignorance and ambiguity they feel about the financial market, Chinese consumers can easily be prevented from owning risky assets.Small share of funds equivalent to undesirable activity in low participation in hazardous assets and illiteracy and strong risk aversion.Financial literacy is not considered an important determinant in families' decision-making regarding risky assets.Excluding background risk factors caused by labor income uncertainty, health risk and home ownership [53].

\section{Investment Decisions}

Investment decision is concerned with the optimal use of funds to maximize the wealth of the company and its shareholders. The investment decision is very important for a company to achieve its objectives; In fact, it generates revenue and ensures the long-term existence of the company. An investment portfolio can have two or more assets. Every investor wants to make optimal investment decisions, optimal and rational investment decisions depend on advanced financial knowledge. Standard Finance, as noted in the literature review, Horistic-driven biases undoubtedly affect investor investment decisions in the financial markets, especially the stock markets, as well as have a significant impact on investment performance. Based on principles and evidence of interval analysis, advanced financial literacy can have a significant impact on investment decisions and the performance of individual investors. More obviously, overconfidence in investment decision-making and performance has a significant negative impact on horistic. When investors use excessive confidence by adding more Their negative impact on financial knowledge, investment decision making and performance is eliminated [12]. These findings continue to illustrate the impact that millennials have had on aging in a turbulent Social and economic context, often finite financial knowledge. With a greater understanding of the millennial segment, marketers can better manage the financial sensibilities of millennials and improve their investment results.Most tasks in the financial risk tolerance area focus on individual public finance investment decisions, and studies of these results demonstrate that risk-tolerant individuals prefer higher risk investments and that investment decisions made by highly financially literate consumers should not be equally affected by risk [26]. Investors make investment decisions based on current news, recent financial position and market reputation. According to investors, any announcement by the company will be affected. Their investment decisions are modified according to the current news prevailing in the market. Such an overreaction in the market yields above average returns to investors. The level of market over-reaction is positively correlated with previous earnings announcements, indicating that there is a representative hierarchy in investor decisions in stock market trading. Representative Horistic can be defined for secondary market data measurement, as investment decisions are made using the latest information related to earned announcements. Therefore, market overreaction, which is defined as representative horticulture, is measured using extraordinary returns due to earned announcements [45]. To maximize the overall yield, farmers pay more attention to the optimal allocation of production factors. At the same time, the comparison between the decline in investment and the stable; The ratio of agricultural income has a significant impact on investment decisions. Coefficient -0.0112 ; That is, for each unit increase in the rate of agricultural income, the probability of farmers reducing investment is reduced to $1.12 \%$, which means that a higher percentage of agricultural income generally represents a smaller proportion of part-time farmers and non-farmers. Employment and farmers' investment in grain production are declining [73]. To use LCC in investment decisions for buildings, decision makers need to realize the benefits of using it. As the decision-makers 'ability to process a small amount of complex information is limited and there is a lack of focus on new issues such as the environmental problem, the LCC, as activists suggest. The LCC approach is generally to environmental decision making, especially to environmental considerations in formulating investment decisions [83]. For instance, recently recruited representatives might talk more to other recently employed workers than to the set up workers, as well as the other way around. Additionally, if the set up representatives have effectively settled on their 
choices, they are less inclined to be impacted by what the recently recruited workers do (on the grounds that after quite a while the outcomes have as of now changed) Women can talk more to ladies than men, and men talk more. For men more than ladies [84]. Albeit these investigations have an unmistakable legitimacy in bringing the viewpoint of financial backers into the image, they areElectric Renewable Energy Department. Also, the greater part of this writing centers around open money. Hence, unmistakably venture choices and strategies influencing speculation choices should be assessed as far as their capacity to ensure broadening even inside the arrangement of RE innovations. The genuine energy is completely uncovered. Besides, see what various elements mean for RE venture results at a coordinated level, yet in addition through innovation, on the grounds that the elements that favor the utilization of one specific innovation may not really uphold another. Environmentally friendly power choices RE speculation results at an incorporated level, yet additionally through innovation, in light of the fact that the variables that favor the utilization of one specific innovation may not really uphold another. Environmentally friendly power choices [85]. The Observatory gathers information on the speculation styles of people, which are ordered as follows: selfcoordinated venture results; Informal counsel (for example picking with family/companions/partners); Investing subsequent to counseling a specialist; Appointing a specialist (a remaining sort incorporates blended speculation rehearses). The second is characterized as the befuddle between people's self-evaluation capacity and real monetary information. In the subtleties, we looked at the respondents' appraising on 'Understanding Basic Financial Products' and' Making Good Investment Decisions' with their comprehension of monetary essentials and monetary numbers as estimated by one of the monetary education (NCA, WACA) markers referenced previously. Furthermore, FA). High confidence is addressed by a pseudo-HSA, which is identical to assessing a respondent's capacity to comprehend fundamental monetary items and settle on preferred venture choices over normal [87].

\section{Investment Choices}

Stocks, protections, shared assets and ETFs are the most well-known sorts of resources. These incorporate the sort of property you pick when putting resources into a retirement reserve funds plan or school reserve funds plan. Other property types incorporate land, valuable metals and different products, and private value. It is certain that a low degree of monetary education drives people to settle on problematic monetary decisions and commit monetary errors. On the property side of the family accounting report, poor monetary proficiency influences reserve funds and venture choices, abundance aggregation, admittance to monetary business sectors and portfolio decisions. A binary profit recession model was used in this study, where family investment choices (dependent variables) are considered as separate choices, on the one hand, financial literacy helps families make well-known financial decisions about investments and savings, and helps to make them. Reducing future financial risks associated with financial services and products [19]. Aside from the theory of rational selection, behavioral financial aspects has created and secured itself as an exploration part of financial aspects today, portraying a considerable lot of the circumstances in which intellectual inclinations lead to unreasonable ends. Albeit the suspicions of sane determination hypothesis are important for a predictable arrangement of monetary and monetary training, the instructive relationship of conduct financial aspects has, until this point, not been officially evolved. Two methodologies Rational selection aside Rational selection theory is a kind of educational export success for the economy because today approaches in other fields of education work with this theory, e.g. Economic analysis of general selection theory or law. On the other hand, this approach has been criticized from various academic perspectives since the days of the theory of rational selection [27]. Likewise, we don't try to at the same time address the normal issue of individual security choice, the division of property among homegrown and global resources, and cash supporting. Despite the fact that we trust that there might be fascinating relationships between's portfolio choice and supporting outcomes because of complaint hatred and that disdain might influence value property costs, we don't address these significant issues in the current work. While money supporting advances our archive, we will clarify how the proposed equation applies to other single-end venture choices, for example the resource portion choice hypothesis among protections and stocks, that the bend of circulation seriously influences speculation decisions. Conventional use. The positive bend persuades financial backers to expand their commitment to unsafe resources. This is an exact ramifications of the LA and DA models [145]. The lack of a practical adjustment that guides managers to face the absolute risks underlying their initiatives explicitly and explicitly — that is, the mechanisms by which our experiments vary from individual to overall conditions — can be expected to affect decision makers and their companies' overconfidence in partners. , Greater investment in joint ventures and management under relationship. All things considered, the topic of this review isn't so much for directors to stay away from related freedoms; Rather, it is tied in with guaranteeing that decisions about reliant freedoms are drawn nearer with maximum capacity acknowledgment of possible conditions and their results [144]. The second case - from the Hungarian Department of Chemicals - operates on the largest example of M\&A's relatively rare Chinese selection in the CEE. Next, the third and longest case, CEE, is dedicated to the most important means of Chinese internationalization in greenfield investment, as going it alone is risky and M\&A opportunities are scarce. Here, the focus is on the Bulgarian automotive industry, but the article adds information about several minor cases in light of the importance of this entry system. FDI decisions are not made in a vacuum but represent uniquely decisive choices on the strategy for internationalization [126].

\section{Conclusion}

Investment behavior is based on uncertainty about the future and is thus risky. The speed and availability of news Rumors and information play an important role in investment markets. Danger pursuit, risk aversion And attitude are key concepts and interpretations of venture conduct. Venture conduct depends on vulnerability about the future and is hence unsafe. Reports on worldwide direct speculation patterns center around ongoing turns of events. 1 Such data is extremely pertinent to policymakers and others keen on the speed and degree of globalization. It has neglected to give any viewpoint on the idea of globalization. By their actual nature, ongoing turns of events are putting more weight on rotating components in global investment flows. They sought to describe diagnostic behaviors and experiences, volunteering, repercussions and experiences they seemed to guess at their risk preference. We found that third-party readers of respondents 'brief memories and 
explanations reached similar assumptions about respondents' preferences, indicating that this information is intermediate valid. Our results help to open up the self-awareness behind the stated risk options, allowing people to develop their own understanding of what diagnostic behaviors and experiences are expressed in high-role situations in the real world. The wealth of the organization and the wealth of its shareholders. The investment decision is very important for a company to achieve its objectives; In fact, it generates revenue and ensures the long-term existence of the company. An investment portfolio can have two or more assets. The most common types of assets are stocks, securities, mutual funds and ETFs. These include the type of property you choose when investing in a retirement savings plan or college savings plan. Other property types include real estate, precious metals and other commodities, and private equity.

\section{Reference}

1. Jorgenson, Dale W. "Econometric studies of investment behavior: A survey." Journal of Economic literature 9 , no. 4 (1971): 1111-1147.

2. Shiv, Baba, George Loewenstein, Antoine Bechara, Hanna Damasio, and Antonio R. Damasio. "Investment behavior and the negative side of emotion." Psychological science 16, no. 6 (2005): 435-439.

3. Grinblatt, Mark, and MattiKeloharju. "The investment behavior and performance of various investor types: a study of Finland's unique data set." Journal of financial economics 55, no. 1 (2000): 43-67.

4. Hira, Tahira K., and CäziliaLoibl. "Gender differences in investment behavior." In Handbook of consumer finance research, pp. 253-270. Springer, New York, NY, 2008.

5. Eisner, Robert, and M. IshaqNadiri. "Investment behavior and neo-classical theory." The review of economics and statistics (1968): 369-382.

6. Salim, A., and S. Khan. "The effects of factors on making investment decisions among Omani working women." Accounting 6, no. 5 (2020): 657-664.

7. Hanson, Thomas A., and Peter M. Olson. "Financial literacy and family communication patterns." Journal of Behavioral and Experimental Finance 19 (2018): 64-71.

8. Bucher-Koenen, Tabea, and Michael Ziegelmeyer. "Once burned, twice shy? Financial literacy and wealth losses during the financial crisis." Review of Finance 18, no. 6 (2014): 2215-2246.

9. Scherner, Jonas. "'Armament in depth'or 'armament in breadth'? German investment pattern and rearmament during the Nazi period 1." The Economic History Review 66, no. 2 (2013): 497-517.

10. Kameoka, Akio, and S. Takayanagi. "A" corporate technology stock" model-determining total R\&D expenditure and effective investment pattern." In Innovation in Technology Management. The Key to Global Leadership. PICMET'97, pp. 497-500. IEEE, 1997.

11. Mudzingiri, Calvin, John W. MutebaMwamba, and Jacobus Nicolaas Keyser. "Financial behavior, confidence, risk preferences and financial literacy of university students." Cogent Economics \& Finance 6, no. 1 (2018): 1512366.

12. Nguyen, Linh, Gerry Gallery, and Cameron Newton. "The joint influence of financial risk perception and risk tolerance on individual investment decision-making." Accounting \& Finance 59 (2019): 747-771.

13. Palmer, Joshua C., Yunhyung Chung, Youngkyun Park, and Gang Wang. "Affectivity and riskiness of retirement investment decisions." Personnel Review (2020).

14. Tong, Suk Chong. "Perceived risk and the interplay of expert endorsement, corporate image and investment knowledge in mutual fund advertising." Journal of Financial Services Marketing 23, no. 3 (2018): 179-189.

15. Khan, Mostafa Saidur Rahim, Naheed Rabbani, and Yoshihiko Kadoya. "Is Financial Literacy Associated with Investment in Financial Markets in the United States?." Sustainability 12, no. 18 (2020): 7370.

16. Yang, Songling, Muhammad Ishtiaq, and Muhammad Anwar. "Enterprise risk management practices and firm performance, the mediating role of competitive advantage and the moderating role of financial literacy." Journal of Risk and Financial Management 11, no. 3 (2018): 35.

17. Liao, Li, Jing Jian Xiao, Weiqiang Zhang, and Congyi Zhou. "Financial literacy and risky asset holdings: evidence from China." Accounting \& Finance 57, no. 5 (2017): 1383-1415.

18. Ahmad, Maqsood, and Syed Zulfiqar Ali Shah. "Overconfidence heuristic-driven bias in investment decision-making and performance: mediating effects of risk perception and moderating effects of financial literacy." Journal of Economic and Administrative Sciences (2020).

19. Larson, Lindsay RL, Jacqueline K. Eastman, and Dora E. Bock. "A multi-method exploration of the relationship between knowledge and risk: The impact on millennials' retirement investment decisions." Journal of Marketing Theory and Practice 24, no. 1 (2016): 72-90.

20. Parveen, Shagufta, ZoyaWajidSatti, Qazi Abdul Subhan, and Sana Jamil. "Exploring market overreaction, investors' sentiments and investment decisions in an emerging stock market." Borsa Istanbul Review 20, no. 3 (2020): $224-235$.

21. Wang, Shuangjin, Yuan Tian, Xiaowei Liu, and Maggie Foley. "How farmers make investment decisions: Evidence from a farmer survey in China." Sustainability 12, no. 1 (2020): 247.

22. Gluch, Pernilla, and Henrikke Baumann. "The life cycle costing (LCC) approach: a conceptual discussion of its usefulness for environmental decision-making." Building and environment 39, no. 5 (2004): 571-580.

23. Duflo, Esther, and Emmanuel Saez. "Participation and investment decisions in a retirement plan: The influence of colleagues' choices." Journal of public Economics 85, no. 1 (2002): 121-148. 
Jaya K R. et.al / Recent trends in Management and Commerce Vol:2(1), 2021: 26-31

24. Masini, Andrea, and EmanuelaMenichetti. "Investment decisions in the renewable energy sector: An analysis of nonfinancial drivers." Technological Forecasting and Social Change 80, no. 3 (2013): 510-524.

25. Gentile, Monica, Nadia Linciano, and Paola Soccorso. "Financial advice seeking, financial knowledge and overconfidence." Evidence from Italy, Consob Research Papers 83 (2016).

26. Lotto, Josephat. "Towards Improving Households' Investment Choices in Tanzania: Does Financial Literacy Really Matter?." International Journal of Financial Studies 8, no. 2 (2020): 29.

27. Loerwald, Dirk, and Arne Stemmann. "Educational Implications of Biases in Financial Decision Making." (2016).

28. Michenaud, Sébastien, and Bruno Solnik. "Applying regret theory to investment choices: Currency hedging decisions." Journal of International Money and Finance 27, no. 5 (2008): 677-694.

29. Adner, Ron, and Daniel Feiler. "Interdependence, perception, and investment choices: An experimental approach to decision making in innovation ecosystems." Organization Science 30, no. 1 (2019): 109-125.

30. Jacoby, Wade. "Different cases, different faces: Chinese investment in Central and Eastern Europe." Asia Europe Journal 12, no. 1-2 (2014): 199-214. 